\title{
Analytics and decision-making to inform public policy in response to diverse threats
}

\author{
Zachary A. Collier ${ }^{1}$. James H. Lambert ${ }^{2} \cdot$ Igor Linkov $^{3}$
}

Published online: 5 November 2020

( ) This is a U.S. Government work and not under copyright protection in the US; foreign copyright protection may apply 2020

The year 2020 has faced a global health pandemic, wildfires, an active hurricane season, and widespread civil unrest. These and other sources of risk have emphasized the importance of using analytics and modeling to support policy for public health, infrastructure, economic policy, and other issues related to the public sphere. The research presented in this issue of the Springer journal Environment Systems \& Decisions supports these goals by advancing methodological and theoretical knowledge in emerging areas such as machine learning and blockchain technology.

The first two articles leverage machine learning approaches. Varghese et al. (2020) deployed deep learning to the problem of text classification, analyzing over 7000 scientific abstracts on the chemical arsenic. They compared the performance of deep learning algorithms to other machine learning techniques, and discussed the strengths and weaknesses of each. Bambil et al. (2020) compared deep learning to other machine learning techniques, with an application of identification of plant species from images of leaves. The authors further compared image capture methods including scanners and mobile phone cameras, finding that the algorithms performed similarly in each case.

The next several articles cover a broad array of mathematical modeling and decision-making methods. Kolagar et al. (2020) utilized a data envelopment analysis approach for prioritizing renewable energy sources. They considered technical, economic, environmental, social, and political criteria in their prioritization approach. Vannarath and Talla (2020) implemented a multi-criteria decision analysis model to the problem of biogas conversion. Seven alternative pretreatment methods were evaluated along five relevant

Igor Linkov

Igor.Linkov@usace.army.mil

Radford University, Radford, VA, USA

University of Virginia, Charlottesville, VA, USA

3 US Army Engineer Research and Development Center, Concord, MA, USA criteria. Next, Collins et al. (2020) leveraged multivariate statistics to determine what makes a city amenable to cycling. Geographic, meteorological, and socioeconomic data were analyzed using a multivariate regression analysis, and the authors provided insights for city planners. Sadeghi et al. (2020) described the problem of expanding electricity generation capacity under uncertain demand and supply conditions. The authors formulated the issue as a multi-objective optimization problem, with objectives of minimizing expected system cost and minimizing expected pollution costs.

The final articles in this issue cover managerial and social aspects of complex systems. Mandić (2020) explored the challenges associated with promoting sustainable eco-tourism in protected natural areas. The driver-pressure-stateimpact-response (DPSIR) framework was implemented as a means for understanding the strategic factors associated with tourism. Gigliotti et al. (2020) explored the relationship between the trust that landowners have in their state department of natural resources and their wildlife value orientations. Using the Minnesota prairie ecosystem as an example, the authors found three clusters of landowners based on their reported trust levels. Walpole et al. (2020) conducted a mental models study of ecological restoration practitioners with the goal of understanding how ecological restoration was conceptualized by those who practice it. The authors found that the practitioners held a deep understanding of ecological principles, but placed less emphasis on social and economic issues such as monitoring and adaptive management. Finally, Teh et al. (2020) discussed how sustainability in corporations needs to be better aligned with organizational capabilities, including strategy, structure, systems, shared values, skills, staff, and style. Following this discussion, blockchain technology was proposed as a potential means of implementing life cycle assessment within an organization to meet sustainability goals. 


\section{References}

Bambil D, Pistori H, Bao F, Weber V, Alves FM, Conçalves EG, Figueiredo LFA, Abreu UGP, Arruda R, Bortolotto IM (2020) Plant species identification using color learning resources, shape, texture, through machine learning and artificial neural networks. Environ Syst Decis. https://doi.org/10.1007/s10669-020-09769-w

Collins AJ, Jordan CA, Robinson RM, Cornelius C, Gore R (2020) Exploring good cycling cities using multivariate statistics. Environ Syst Decis. https://doi.org/10.1007/s10669-019-09753-z

Gigliotti LM, Sweikert LA, Cornicelli L, Fulton DC (2020) Minnesota landowners' trust in their department of natural resources, salient values similarity and wildlife value orientations. Environ Syst Decis. https://doi.org/10.1007/s10669-020-09766-z

Kolagar M, Hosseini SMH, Felegari R, Fattahi P (2020) Policy-making for renewable energy sources in search of sustainable development: a hybrid DEA-FBWM approach. Environ Syst Decis. https ://doi.org/10.1007/s10669-019-09747-x

Mandić A (2020) Structuring challenges of sustainable tourism development in protected natural areas with driving force-pressurestate-impact-response (DPSIR) framework. Environ Syst Decis. https://doi.org/10.1007/s10669-020-09759-y
Sadeghi Z, Hatami Y, Jalaei SA, Abdollahi A (2020) Generation capacity expansion economic-environmental planning under uncertainty of demand and supply. Environ Syst Decis. https:// doi.org/10.1007/s10669-020-09758-Z

Teh D, Tehmina K, Corbitt B, Ong CE (2020) Sustainability strategy and blockchain-enabled life cycle assessment: a focus on materials industry. Environ Syst Decis. https://doi.org/10.1007/s1066 9-020-09761-4

Vannarath A, Talla AK (2020) Evaluation, ranking, and selection of pretreatment methods for the conversion of biomass to biogas using multi-criteria decision-making approach. Environ Syst Decis. https://doi.org/10.1007/s10669-019-09749-9

Varghese A, Agyeman-Badu G, Cawley M (2020) Deep learning in automated text classification: a case study using toxicological abstracts. Environ Syst Decis. https://doi.org/10.1007/s1066 9-020-09763-2

Walpole EH, Toman E, Stidham M, Wilson R (2020) The science and practice of ecological restoration: a mental models analysis of restoration practitioners. Environ Syst Decis. https://doi.org/10.1007/ s10669-020-09768-x 